\title{
Long-Term Lung Function and Exercise Capacity in Postinfectious chILD
}

\author{
Yagmur Sisman, MD, Frederik F. Buchvald, MD, PhD, ${ }^{1}$ Astrid Madsen Ring, MD, \\ Katharina Wassilew, MD, DMSc, ${ }^{2}$ and Kim Gjerum Nielsen, MD, DMSc ${ }^{1}$
}

Background: Severe postinfectious diffuse pulmonary disease may clinically mimic other entities of children's interstitial lung disease and is clinically challenging comprising various disease severities despite treatment. Long-term lung function trend and physical capacity in children with postinfectious diffuse pulmonary disease are rarely reported. We investigated trends in pulmonary function by long-term follow-up and assessed physical capacity in such patients. Methods: We performed a descriptive, single-center follow-up study in children with biopsy-verified postinfectious diffuse pulmonary disease. Patients with completed primary treatment course were eligible for followup, including pulmonary function and exercise $\left(\mathrm{VO}_{2 \text { peak }}\right)$ testing.

Results: Thirty patients with postinfectious diffuse pulmonary disease were identified and included. Median (range) age at diagnose was 27.5 (2-172) months after a mean lag time of 23 months. H. influenzae and rhinovirus were the most frequent pathogens. Fifteen patients were available for follow-up after mean (range) 7.6 (2-15) years of treatment completion. Lung clearance index $\left(\mathrm{LCI}_{2.5}\right)$, forced expiratory volume in 1 second $\left(\mathrm{FEV}_{1}\right)$, and bronchodilator responsiveness were abnormal in $80 \%, 53 \%$, and $44 \%$, respectively. Diffusion capacity for monoxide was abnormal in $7 \%$ and total lung capacity in $33 \%$. Only $8 \%$ demonstrated low $\mathrm{VO}_{2 \text { peak }}$, while $40 \%$ reported difficulties during physical exertion. Longitudinal data on spirometry $(n=14)$ remained unchanged from end of treatment throughout follow-up. A significant association was found between $\mathrm{zLCI}_{2.5}$ and $\mathrm{zFEV}_{1}$ (multiple linear regression; $r^{2}=0.61 ; P=0.0003$ ).

Conclusion: Postinfectious diffuse pulmonary disease in children carries a varying degree of chronic pulmonary impairment with onset of symptoms in the first months of life and a typical considerable lag time before diagnosis. Follow-up several years after the initial injury demonstrated moderate-to-severe peripheral airway impairment although no further lung function decline was found years after completion of treatment. Despite acceptable $\mathrm{VO}_{2 \text { peak }}$, a considerable proportion struggled during heavy exercise.

Keywords: childhood interstitial lung disease, diffuse lung disease, pulmonary function test, exercise capacity, children

\section{Introduction}

$\mathrm{P}$ OSTINFECTIOUS DIFFUSE PULMONARY disease with chronic lung impairment has traditionally been associated with classic postinfectious bronchiolitis obliterans (PIBO), which is an obstructive lung disease, leading to partial or complete small airway occlusion, sometimes occurring in children following a severe lower respiratory tract infection. ${ }^{1-3}$

Clinical diagnosis of classic PIBO is based on the persistence of tachypnea, wheezing, and/or hypoxemia for at least 6 weeks following severe bronchiolitis or pneumonia. Characteristic radiological findings include air trapping, hyperinflation, mosaic pattern, bronchial wall thickening, and bronchiectasis, and pulmonary function testing reveals obstructive lung function. ${ }^{1,4,5}$ The diagnosis is histopathologically characterized by a distinctive pattern of peribronchiolar fibrosis that ultimately results in complete obliteration of the bronchiolar lumen. ${ }^{1}$

Treatment options are limited and based on empirical evidence and these therapies reportedly yield disappointing

\footnotetext{
${ }^{1}$ Danish chILD Centre, Paediatric Pulmonary Service, Copenhagen University Hospital, Rigshospitalet, Copenhagen, Denmark.

${ }^{2}$ Department of Pathology, Copenhagen University Hospital, Rigshospitalet, Copenhagen, Denmark.

The work was performed at: The Danish chILD Centre, Paediatric Pulmonary Service, Copenhagen University Hospital, Rigshospitalet, Copenhagen, Denmark.

(C) Yagmur Sisman et al. 2019; Published by Mary Ann Liebert, Inc. This Open Access article is distributed under the terms of the Creative Commons Attribution Noncommercial License (http://creativecommons.org/licenses/by-nc/4.0/) which permits any noncommercial use, distribution, and reproduction in any medium, provided the original author(s) and the source are cited.
} 
responses, and affected children show a high persisting morbidity rate. ${ }^{1,6}$ However, long-term data and prognostic information are limited to a few case series, none of which focuses on peripheral airway impairment and physical ability, and are mainly focused on the classical form of PIBO and not a broader spectrum of postinfectious diffuse pulmonary disease mimicking other severe diffuse lung diseases. ${ }^{7-10}$ Such children may have less severe chronic intractable disease although phenotypical characteristics similar to patients with classic pathohistological pattern of PIBO.

Our aim was to investigate detailed clinical and pathohistological characteristics at baseline and perform comprehensive assessment of pulmonary function and fitness at follow-up in a cohort of children with chronic postinfectious diffuse pulmonary disease in a broader term to estimate long-term pulmonary impairment and monitor changes over time. We hypothesized that spirometry values would remain severely impaired, showing an obstructive pattern and that lung clearance index $\left(\mathrm{LCI}_{2.5}\right)$ and peak oxygen uptake $\left(\mathrm{VO}_{2 \text { peak }}\right)$ would show diminished values, while diffusing capacity (DLco) and physical exertion would likely be unaffected.

\section{Materials and Methods}

\section{Study design and patient population}

This descriptive, single-center follow-up study included children and young adults with a biopsy-verified diagnosis of postinfectious diffuse pulmonary disease according to criteria listed below. Cases were retrieved from the local database and by searching the Discharge Register of Copenhagen University Hospital (Rigshospitalet). The search was limited to cases with onset $<16$ years of age, registered between January 1998 and December 2015.

Patients who had completed their primary treatment course and were continued on medication-such as hydrocortisone substitution, inhaled asthma medication, (bronchodilators and corticosteroids) or azithromycin-were eligible to participate in the follow-up part consisting of one study visit. The visit was postponed for at least 2 weeks in case of respiratory tract infection within the past 14 days. Exclusion criteria were reduced ability to provide informed consent and inability to cooperate to spirometry or nitrogen multiple-breath washout $\left(\mathrm{N}_{2} \mathrm{MBW}\right)$.

\section{Retrospective data}

The clinical diagnostic criteria for inclusion were a combination of the following: history of severe infection (pneumonia/bronchiolitis); clinical features associated with diffuse lung disease (tachypnea, wheezing, and/or hypoxemia) persisting at least 6 weeks; characteristic high resolution computed tomography (HRCT) findings (air trapping, hyperinflation, and mosaic pattern); and lung biopsy excluding other diffuse lung diseases, such as neuroendocrine hyperplasia of infancy (NEHI), pulmonary interstitial glycogenosis (PIG), surfactant disorders, or other well-known pathohistological entities within children's interstitial lung diseases. ${ }^{11}$ Electron microscopy of lung biopsy material and analysis of inflammatory cells in bronchoalveolar lavage (BAL) fluid were sometimes performed although not part of the routine workup.
Significant immunodeficiency was excluded by basic screening, including white blood cell counts, immunoglobulins and subclasses, and mannose-binding lectin (MBL). Selected cases were subjected to an extended workup that included lymphocyte marker analysis, complement, and somatic hypermutation.

Previous pulmonary measurements were retrieved from the hospital database.

As this was not a controlled prospective study, no specified treatment protocol was applied. Treatment regimens were individualized and based on predominant symptoms and disease severity.

\section{Follow-up visit}

Pulmonary function and exercise tests. $\mathrm{N}_{2} \mathrm{MBW}$ was performed using Exhalyzer D (Eco Medics AG, Duernten, Switzerland) and its associated software (Spiroware 3.1.6 ext., Eco Medics AG), ${ }^{12}$ and $\mathrm{LCI}_{2.5}$ was the primary outcome. $\mathrm{LCI}_{2.5}, \mathrm{~S}_{\text {cond }}$, and $\mathrm{S}_{\mathrm{acin}}$ (Scond and Sacin are indices of ventilation heterogeneity in the conductive and acinar lung zones) were measured in accordance with the consensus statement of the European Respiratory Society (ERS)/American Thoracic Society (ATS). ${ }^{13,14}$ For each patient, the mean $\mathrm{LCI}_{2.5}$ from three runs of $\mathrm{N}_{2} \mathrm{MBW}$ measurements was used for analysis. Spirometry, diffusing capacity (DLco), and body plethysmography were performed using Jaeger Master Screen Pro (Carefusion, Hochberg, Germany) according to ATS and ERS recommendations. ${ }^{15-18}$ Bronchodilator responsiveness (BDR) was assessed using $400 \mu \mathrm{g}$ inhaled salbutamol, and significant BDR was defined as $\geq 12 \%$ increase in forced expiratory volume in 1 second $\left(\mathrm{FEV}_{1}\right) .{ }^{19}$

Fitness in terms of peak oxygen uptake $\left(\mathrm{VO}_{2 \text { peak }}\right)$ was assessed during an incremental exercise test on an electronically braked cycle ergometer, as previously described. ${ }^{20}$

A more detailed description of pulmonary function testing and exercise testing is available online (Supplementary Data S1).

Questionnaire. We created a short questionnaire covering various respiratory symptoms and physical activity limitations. The questions were related to the past 2 weeks before the visit. Description of the design of the questionnaire and the questionnaire is available online (Supplementary Data S1 and S2).

\section{Statistics}

Statistical analysis was performed using MedCalc Version 16.2.1 (MedCalc Software, Mariakerke, Belgium). Follow-up data were compared to baseline using paired $t$-test. Lower limit of normal (LLN) were defined as a $z$-score $<-1.64$ (spirometry, diffusing capacity, and $\mathrm{VO}_{2 \text { peak }}$ ), and upper limit of normal (ULN) was defined as $z$-score $>1.64\left(\mathrm{LCI}_{2.5}\right)$. Linear regression was performed for continuous parameters. $P$-value $<0.05$ was considered statistically significant. Covariates found to be significant in univariate analysis were included in multiple linear regression analysis, with stepwise forward and backward selection to analyze how $\mathrm{N}_{2} \mathrm{MBW}$ indices and $\mathrm{VO}_{2 \text { peak }}$ were related to other parameters.

\section{Ethics}

This study was approved by the Research Ethics Committee of the Capital Region of Denmark (J. no. H-4-2013-154) and the Danish Data Protection Agency (J. no. 30-1142, ID 
no. 02838). Written informed consent was obtained from patients $>18$ years and from the legal guardians of all participants $<18$ years.

\section{Results}

\section{Characteristics of all patients}

Thirty patients fulfilled the inclusion criteria. None of the patients suffered from any comorbidity such as cardiac, metabolic, or neurological disease. Twenty-eight patients were born at term, one at gestational age (GA) of 33, and one at GA of 35 weeks. Four had mild respiratory distress syndrome (including the child with a GA of 33 weeks). The mean birth weight (range) was $3.407 \mathrm{~kg}$ (1.676-5.050). Twenty-nine patients had completed treatment and 25 were eligible for the follow-up analysis. Seventeen patients consented to participate in the follow-up study, but two were not able to cooperate to the tests (Fig. 1).

\section{Retrospective data}

The median (range) age at onset of persistent respiratory symptoms in the initial cohort of 30 patients was $4.5(0-170$ months) and the median age at diagnosis was 27.5 (2-172) months. Hence, mean lag time of diagnosis was 23 months. Only $36.7 \%$ were diagnosed within 6 months of symptom onset (Supplementary Fig. S1). Before diagnosis, 26.7\% were treated with macrolides, $70 \%$ with other antibiotics, $76.7 \%$ with beta $_{2}$-agonists, $66.7 \%$ with inhaled corticoste- roids, and $30 \%$ with oral corticosteroids. Table 1 outlines the baseline characteristics of patients at first visit.

At diagnosis, all but two patients were investigated with HRCT. The most frequent findings were bronchiectasis $(42.9 \%)$, mosaic perfusion $(60.7 \%)$, atelectasis $(39.3 \%)$, and air trapping (42.9\%). Echocardiography was performed in $66.7 \%$. Pulmonary hypertension indicated by a tricuspid insufficiency gradient $>30 \mathrm{mmHg}$ was found in $15 \%$.

Microbiological assessments of samples from laryngeal swabs or BAL at onset were available from $80 \%$ of children of whom $13 \%$ had negative findings. A wide range of bacteria and viruses were isolated, but the most frequent findings were $H$. influenzae (16.7\%) and rhinovirus (10\%). Details are further outlined online (Supplementary Fig. S2).

All children underwent lung biopsies, predominantly as open lung biopsy procedures (93.3\%). Histology data were missing in $3.4 \%(n=1)$. The overall lung parenchyma architecture was generally preserved, with distortion being mild in $93.3 \%$ of patients, moderate in $6.7 \%$, and severe in $0 \%$. Centrilobular and interstitial inflammatory cell infiltrates predominantly comprised $\mathrm{CD}^{+} / \mathrm{CD}^{+} \mathrm{T}$ lymphocytes. Chronic inflammatory cell infiltrates were primarily located in the interstitium in $50 \%$ of patients and showed peribronchiolar distribution in 46.7\%. Varying degrees of follicular aggregates of $\mathrm{CD} 20^{+} \mathrm{B}$ lymphocytes or reactive germinal center arrangements around the bronchioles were seen in 12 cases $(40 \%)$. One child (3.4\%) showed moderate interstitial fibrosis, 10 children $(34.5 \%)$ showed minor fibrous thickening of alveolar walls, and $19(65.5 \%)$ showed
FIG. 1. Flow diagram of the inclusion and study process of children and young adults with postinfectious diffuse pulmonary disease (PIDPD).

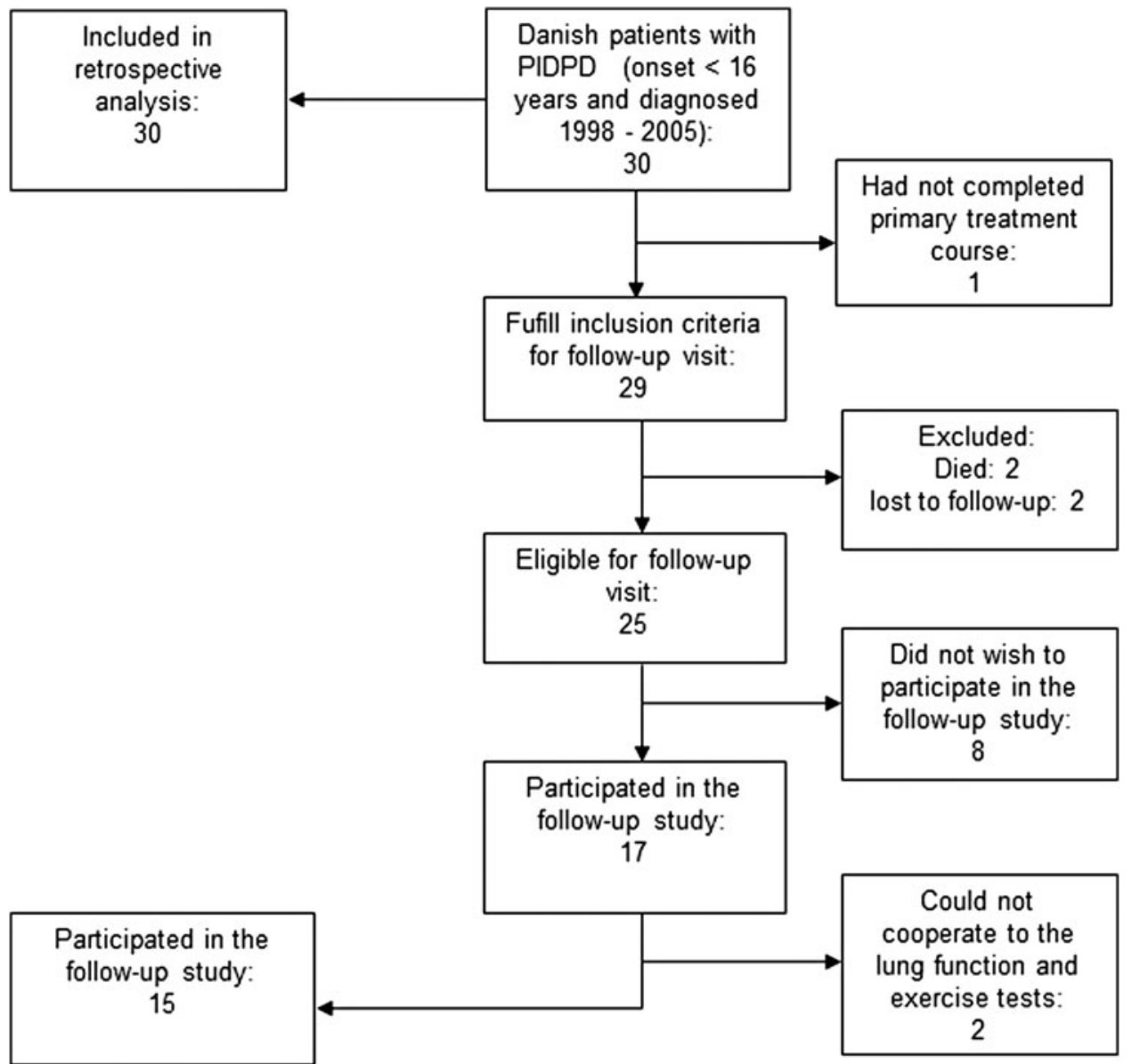


Table 1. Clinical Characteristics at Diagnosis

\begin{tabular}{lc}
\hline$N$ & 30 \\
Gender (M/F) & $17 / 13$ \\
Dyspnea during activity/play/exercise & $73.3 \%$ \\
Cough & $50.0 \%$ \\
Failure to thrive (weight SD <-1.96) & $23.3 \%$ \\
Fever & $6.7 \%$ \\
Wheeze & $40.0 \%$ \\
Tachypnea & $66.6 \%$ \\
Weight (SD), mean (range) & $-0.95(-2.5$ to 1.3$)$ \\
Height (SD), mean (range) & $-0.55(-2.0$ to 1.4$)$ \\
Crackles & $56.7 \%$ \\
Binasal cath oxygen supplementation & $23.3 \%$ \\
Clubbing & $10 \%$ \\
Age at onset (months), & $4.5(0-170)$ \\
$\quad$ mean (range), $n=30$ & \\
Age at diagnosis (months), $\quad$ & \\
mean (range), $n=30$ & $27.5(2-172)$ \\
Age at the end of treatment (years), & $6.5(1-16.3)$ \\
$\quad$ mean (range), $n=30$ & \\
Age at follow-up (years), & \\
$\quad$ mean (range), $n=15$ & $13.0(5.6-27.5)$ \\
Follow-up time (years), & \\
$\quad$ mean (range), $n=15$ & $7.6(2-15)$ \\
\hline
\end{tabular}

$\mathrm{SD}$, standard deviation.

no interstitial fibrosis. Acute or granulomatous inflammation, hyaline membranes, necrotic debris, and foreign material were not observed, and no biopsies showed exclusively classic features seen in PIBO.

Basic screening for latent immunodeficiency was performed in $90 \%$ of patients at diagnosis. Two children exhibited slightly decreased IgG, which was not considered clinically relevant and thus no substitution therapy was required. Extended immune system evaluation was conducted in $86.7 \%$ of the cohort, revealing no major abnormalities. A genotype related to impaired MBL function was found in
10 children $(\sim 30 \%)$. No children were considered to show clinically significant relevant immunoincompetence.

Although treatment varied, all patients received monthly intravenous high-dose pulse methylprednisolone $(n=30)$. Some cases were also administered oral prednisolone, hydroxychloroquine, azathioprine, mycophenolate mofetil, or cyclosporine due to disease severity and insufficient treatment response (Supplementary Table S1).

\section{Patients eligible for follow-up}

The mean period between end of treatment and follow-up in 15 patients lasted 7.6 years. Age at onset, diagnosis, and end of treatment is shown in Table 1.

Pulmonary function. $\mathrm{LCI}_{2.5}, \mathrm{~S}_{\mathrm{cond}}$, and $\mathrm{S}_{\text {acin }}$ were abnormal in $80 \%, 73 \%$, and $80 \%$ of cases. $\mathrm{FEV}_{1}$ was abnormal in $53 \%$, median $z$-score -1.9 . FEV1/FVC median (range) was $0.82(0.4-1.0)$ and was abnormal in $47 \%$, thus indicating an obstructive pattern. Significant BDR was shown in 33.3\%. Table 2 shows additional pulmonary function results.

Longitudinal lung function data (range: $2-15$ years) were additionally available in $14 / 30$ children (Fig. 1). Individual trend curves of $\mathrm{zFEV}_{1}, \mathrm{zFVC}$, and $\mathrm{zFEV}_{1} / \mathrm{FVC}$ are illustrated online (Supplementary Fig. S3). All longitudinally assessed lung function parameters remained unchanged throughout follow-up after completion of treatment (Table 3).

Exercise testing. Table 4 presents the exercise test results. All subjects met the peak exercise criteria, except one patient who could only complete a test duration of $5 \mathrm{~min}$, and one patient who could not cooperate due to young age (5 years). One patient showed abnormal $\mathrm{VO}_{2 \text { peak }}\left(\mathrm{zVO}_{2 \text { peak }}=-2.1\right)$, but all other parameters were normal, and the patient was not considered limited by respiratory conditions. One patient exhibited desaturation $\left(\mathrm{SpO}_{2}<90 \%\right)$ during the last $90 \mathrm{~s}$. This patient had an increased $\mathrm{LCI}_{2.5}$ (13.4), abnormal $\mathrm{zFEV}_{1} / \mathrm{FVC}$ ratio $(-2.48)$, and a $\mathrm{zVO}_{2 \text { peak }}$ in the lower

Table 2. Pulmonary Function at Follow-Up in 15 Patients

\begin{tabular}{|c|c|c|c|c|}
\hline Lung function test & $\begin{array}{l}\text { Abnormal } \\
(\%)\end{array}$ & $\begin{array}{l}\mathrm{z} \text {-score median } \\
\text { (range) }\end{array}$ & $\begin{array}{c}\% \text { Predicted median } \\
(\text { range })\end{array}$ & $\begin{array}{c}\text { Absolute values median } \\
\text { (range) }\end{array}$ \\
\hline \multicolumn{5}{|l|}{$\mathrm{N}_{2} \mathrm{MBW}(N=15)$} \\
\hline $\mathrm{LCI}_{2.5}$ & 80.0 & $10.0(0.5$ to 20.1$)$ & $163(102-372)$ & $10.60(6.80-24.30)$ \\
\hline $\mathrm{S}_{\mathrm{cond}}$ & 73.3 & $2.5(-5.0$ to 10.3$)$ & $150(50-700)$ & $0.025(0.007-0.14)$ \\
\hline $\mathrm{S}_{\mathrm{acin}}$ & 80.0 & $4.0(-0.8$ to 7.6$)$ & $317(83-1100)$ & $0.17(0.048-0.58)$ \\
\hline \multicolumn{5}{|l|}{ Spirometry $(N=15)$} \\
\hline $\mathrm{FEV}_{1}, \mathrm{~L}$ & 47.0 & $-1.9(-5.8$ to 0.0$)$ & $78(27-100)$ & $2.00(0.80-4.60)$ \\
\hline FVC, L & 20.0 & $-1.0(-3.7$ to 1.1$)$ & $87(58-113)$ & $2.53(0.85-6.01)$ \\
\hline MMEF 72 to $75, \mathrm{~L} / \mathrm{s}$ & 46.7 & $-1.5(-6.5$ to 0.4$)$ & $71(8-109)$ & $1.61(0.30-5.07)$ \\
\hline $\mathrm{FEV}_{1} / \mathrm{FVC}$, ratio & 47.0 & $-0.3(-4.7$ to 1.7$)$ & $98(46-108)$ & $0.82(0.40-0.90)$ \\
\hline \multicolumn{5}{|l|}{ Diffusing capacity $(N=15)$} \\
\hline $\mathrm{DL}_{\mathrm{CO}}, \mathrm{mmol} / \mathrm{min} / \mathrm{kPa}$ & 13.3 & $0.4(-3.9 ; 5.1)$ & $107(55,213)$ & $6.9(4.2-13.9)$ \\
\hline $\begin{array}{l}\mathrm{DL} \mathrm{CO}_{\mathrm{CO}} / \mathrm{V}_{\mathrm{A}}, \\
\mathrm{mmol} / \mathrm{min} / \mathrm{kPa} / \mathrm{L}\end{array}$ & 6.7 & $0.0(-0.7 ; 4 ; 7)$ & $100(88-180)$ & $1.9(1.6-3.3)$ \\
\hline \multicolumn{5}{|c|}{ Body plethysmography $(N=15)$} \\
\hline $\mathrm{RV}, \mathrm{L}$ & 26.7 & $2.3(-0.3$ to 4.7$)$ & $134(47-238)$ & $2.66(0.53-6.38)$ \\
\hline TLC, L & 40.0 & $-0.1(-5.5$ to 2.2$)$ & $99(44-122)$ & $1.47(0.47-3,39)$ \\
\hline $\mathrm{VC}, \mathrm{L}$ & 60.0 & $-2.8(-5.7$ to 4.1$)$ & $68(36-145)$ & $4.15(1.30-9.87)$ \\
\hline RV/TLC ratio & 46.7 & $1.8(0.1$ to 5.4$)$ & $144(103-234)$ & $0.35(0.25-0.7)$ \\
\hline
\end{tabular}

$\mathrm{DL}_{\mathrm{CO}}$, single breath diffusing capacity of the lung for carbon monoxide. $\mathrm{DL}_{\mathrm{CO}} / \mathrm{VA}$, diffusion capacity corrected for Alveolar volume; $\mathrm{FEF}_{25-75}$, forced mid expiratory flow; $\mathrm{FEV}_{1}$, forced expiratory volume in $1 \mathrm{~s}$. FVC, forced vital capacity; LCI, Lung Clearance Index; $\mathrm{MBW}, \mathrm{N}_{2}$, nitrogen multiple-breath washout; RV, residual volume; $\mathrm{S}_{\text {acin }}$, Acinar airways ventilatory heterogeneity; $\mathrm{S}_{\text {cond }}$, conductive airways ventilatory heterogeneity; TLC, total lung capacity; VC, vital capacity. 
Table 3. Longitudinally Assessed Parameters From End of Treatment Until Last Follow-Up Visit (Mean Follow-Up Period of 6.2 Years)

\begin{tabular}{lccc}
\hline $\mathrm{N}=14$ & End of treatment, median (range) & Last visit, median (range) & Paired T-test \\
\hline ZFEV $_{1}$ & $-2.64(-5.73$ to 1.69$)$ & $-2.72(-6.17$ to 0.38$)$ & $P=0.83$ \\
ZFVC $_{\text {zFEV }_{1} / \mathrm{FVC}}$ & $-1.34(-3.07$ to 1.37$)$ & $-1.15(-3.70$ to 0.65$)$ & $P=0.86$ \\
\hline
\end{tabular}

$\mathrm{FEV}_{1}$, forced expiratory volume in $1 \mathrm{~s} ; \mathrm{FVC}$, forced vital capacity.

normal range $(-1.45)$, but all other lung function parameters were normal.

Linear regression revealed no significant association between $\mathrm{zVO}_{2 \text { peak }}$ and any pulmonary function parameters. The final multiple linear regression model (adjusted $\left.R^{2}=0.61\right)$ confirmed a significant association between $\mathrm{zLCI}_{2.5}$ and $\mathrm{zFEV}_{1}(P=0.0005)$.

\section{Self-reported respiratory symptoms and activity level}

Among patients who reported "feeling breathless," the majority mentioned sports and heavy play activities as primary triggers $(87 \%)$. Difficulties during these activities were reported by $40 \%$, while $53 \%$ had no respiratory difficulties during physical exercise. However, most subjects were physically active; $53 \%$ for $5-7 \mathrm{~h}$ in an average week, and $27 \%$ for 3-4h/week (Supplementary Data S3).

\section{Discussion}

The present results demonstrated chronic lung function impairment in our cohort of children diagnosed with postinfectious diffuse pulmonary disease documented by varying degree of both bronchiolar and/or interstitial/alveolar histological abnormalities in lung biopsy and structural changes on HRCT. Most cases had onset very early in life with considerable heterogenous microbiological pathogens and varying lag time until diagnosis. Patients with longitudinal data and/or eligible for follow-up exhibited persistent abnormal spirometry and abnormal $\mathrm{N}_{2} \mathrm{MBW}$ indices many years after the initial infectious injury. Despite airway im-

Table 4. Peak Oxygen Uptake Results IN 13 PATIENTS

\begin{tabular}{|c|c|c|}
\hline & Median & Range \\
\hline $\mathrm{VO}_{2 \text { peak }}, \mathrm{mL} / \mathrm{kg} / \mathrm{min}$ & 42.5 & $32.3-53.4$ \\
\hline $\mathrm{VO}_{2 \text { peak }}, \mathrm{mL} / \mathrm{kg} / \mathrm{min}, \%$ predicted & 89.6 & $69.9-115.6$ \\
\hline $\mathrm{VO}_{2 \text { peak }}, \mathrm{mL} / \mathrm{kg} / \mathrm{min}, z$-scores & -0.77 & $-2.1-1.1$ \\
\hline $\mathrm{V}_{\mathrm{E}}, \mathrm{L} / \mathrm{min}(\mathrm{BTPS})$ & 61.4 & $43.2-156.0$ \\
\hline $\mathrm{RF}, \min ^{-1}$ & 48.9 & $20.4-77.3$ \\
\hline RER & 1.15 & $1.1-2.6$ \\
\hline $\mathrm{HR}_{\max }, \mathrm{bpm}$ & 191 & $176-210$ \\
\hline Min. $\mathrm{S}_{\mathrm{pO} 2}, \%$ & 95 & $83-99$ \\
\hline Test duration, min & 7 & $5-11$ \\
\hline $\mathrm{W}_{\max }$, watt & 160 & $50-350$ \\
\hline $\mathrm{W}_{\max / \mathrm{kg}}$ & 3.7 & $2.5-4.7$ \\
\hline $\mathrm{V}_{\mathrm{E}} / \mathrm{V}_{\mathrm{CO} 2}, \%$ & 29.8 & $21.8-50.5$ \\
\hline
\end{tabular}

$\mathrm{HR}_{\text {max }}$, maximal heart rate; Min $\mathrm{S}_{\mathrm{p}} \mathrm{O}_{2}$, oxygen saturation; RER, respiratory exchange ratio; $\mathrm{RF}$, respiratory frequency; $\mathrm{V}_{\mathrm{E}}$, peak minute ventilation; $\mathrm{V}_{\mathrm{E}} / \mathrm{VCO}_{2}$, ventilatory equivalent for $\mathrm{CO}_{2} ; \mathrm{VO}_{2 \text { peak }}$, peak oxygen uptake; $\mathrm{W}_{\max }$, maximal work load. pairment, these children generally showed overall physical ability (estimated by $\mathrm{VO}_{2 \text { peak }}$ ) within the normal range and had a preserved diffusion capacity. Moreover, based on this small cohort of patients with postinfectious diffuse pulmonary disease, the lung condition did not seem to be progressive, as spirometry results were unchanged many years after completion of treatment. Our findings confirmed that postinfectious diffuse pulmonary disease histopathologically is a heterogenous and severe chronic lung condition, characterized by persistent pulmonary impairment (especially peripheral). However, the cohort showed acceptable overall fitness despite $40 \%$ reported feeling breathless playing sports or games.

To our knowledge, this is the first study presenting $\mathrm{N}_{2} \mathrm{MBW}$ and $\mathrm{VO}_{2 \text { peak }}$ data from a cohort with diffuse lung disease categorized as postinfectious diffuse pulmonary disease in a broader term and not just classical PIBO. Colom et al. performed a prospective long-term follow-up study on pulmonary function in a pediatric cohort $(n=46)$ with classic PIBO. $^{7}$ As in our study, they reported severely impaired pulmonary function after a 12-year follow-up period. In contrast to our findings of stable lung function, Cazzato et al. reported decline by $1 \%$ per year in $\mathrm{FEV}_{1}, \mathrm{FVC}$, and $\mathrm{FEV}_{1} /$ FVC over a median follow-up time of 10 years in a study of children with classic PIBO. ${ }^{10}$ It is not possible to explain this contrast in results, but it may be caused by heterogenous patient populations, small sample sizes in both studies (11 in the study by Cazzato et al. and 30 in our study), and different treatment regimens and durations. Mattiello et al. reported $\mathrm{VO}_{2 \text { peak }}$ in 20 children with PIBO. ${ }^{21}$ Mean age in this group was 11 years with no information of clinical condition or medical treatment. Mean (standard deviation) $\mathrm{VO}_{2 \text { peak }}$ was $77.5 \%$ versus $89.6 \%$ in our population. In contrast to our study, they reported a reduced $\mathrm{VO}_{2 \text { peak }}(<85 \%$ predicted) in $11(55 \%)$ patients. The patients included in our study had completed their primary treatment course, but it is uncertain whether this applies for the included patients in the study by Mattiello et al., which may explain the higher level of abnormal values.

$\mathrm{N}_{2} \mathrm{MBW}$ outcomes are more frequently abnormal than $\mathrm{FEV}_{1}$, and $\mathrm{N}_{2} \mathrm{MBW}$ is likely more sensitive than spirometry as marker of significant distal airway involvement in lung diseases. This has been demonstrated in children with primary cilia dyskinesia, hypersensitivity pneumonitis, cystic fibrosis, and in children experiencing allograft rejection after human stem cell transplantation. ${ }^{20,22-24}$ Compared to hypersensitivity pneumonitis, these children with postinfectious diffuse pulmonary disease was dominated by more severely affected $\mathrm{N}_{2} \mathrm{MBW}$ indices and lower $\mathrm{zFEV}_{1}$. Despite the greater obstructive pattern in lung function, only a minority of this cohort showed $\mathrm{VO}_{2 \text { peak }}$, similar to the findings in the hypersensitivity pneumonitis cohort. ${ }^{22}$ Low $\mathrm{VO}_{2 \text { peak }}$ may reflect several different physical limitations 
that are not exclusively related to lung disease. ${ }^{25}$ One patient had abnormally low $\mathrm{VO}_{2 \text { peak }}$, as well as impaired $\mathrm{LCI}_{2.5}$, DLco/VA, and total lung capacity. However, this patient reported that he participated in physical activities without difficulty and was physically active $5-7 \mathrm{~h}$ a week; therefore, we documented no respiratory limitation. This indicates that remarkable overall compensation may be possible and is supported by the finding that the majority of children had only minor subjective respiratory complaints in daily life-apart from "feeling breathless" upon heavy physical exercise, which is commonly reported also by healthy children.

Classic PIBO is a rare disease that has been mainly studied in South America where adenovirus is the predominant cause. ${ }^{7,8,26,27}$ In contrast, adenovirus was a possible causative agent in only $7 \%(n=2)$ of our patient cohort. This difference is likely due to the high prevalence of viral disease in South America, and the lower socioeconomic status, which is related to poor sanitation, lower hygienic practices, indoor smoking, and overcrowding, all of which contribute to facilitating adenovirus transmission. ${ }^{1,28}$ In our cohort, the possible causative infectious agents were reported as contemporary microbiological findings and sometimes of speculative relevance and could thus be considered trivial and not classic infections able to cause chronic lung disease. Therefore, the exact cause of pulmonary disease, although highly likely of infectious nature, was not always elucidated by accessible tests. However, the majority of patients was considered chronically affected with abnormally reduced $\mathrm{FEV}_{1}$ in more than $50 \%$ of patients and increased LCI in $80 \%$. The duration of time from end of treatment to followup visit varies from 2 to 15 years, and therefore, it should be acknowledged that children with shortest follow-up could potentially recover.

Diagnosis of postinfectious diffuse pulmonary disease can be challenging, since it may clinically resemble other diffuse lung diseases, especially in infants and preschool children, with a wide spectrum of severity.

Our present findings support the existence of a disease entity with some diagnostic ambiguity. In many cases, adenovirus or other microbiological agents are not documented, and lung function cannot be assessed due to the young age of onset (although infant MBW measurement may be an option, it was not available at the onset in this study). Furthermore, many of these children show phenotypic overlap with "persistent tachypnea of infancy" or other diseases seen in infancy, such as NEHI and PIG. In unclear cases, HRCT may be useful to exclude other diffuse lung diseases.

Some confusion exists regarding the terminology used for bronchiolar disorders. The basic "injury" may be caused by several factors other than infections, including connective tissue diseases and allograft rejections, and often shows nonspecific histological features regarding etiology. ${ }^{29}$ PIBO is primarily considered an entity with a constrictive pattern, and is pathologically characterized by a distinctive pattern of peribronchiolar fibrosis that ultimately results in complete obliteration of the bronchiolar lumen. ${ }^{1}$ However, our cohort did not exhibit this classic histological pattern, and was instead dominated by signs of follicular bronchiolitis. It is unclear whether this is related to early milder stage of PIBO or something different.

After infection, most healthy children undergo total recovery, including "repair" of the lung epithelial surface area. However, in some children, the repair process seems to fail. In such cases, the final fibrotic remodeling process may result from complex interactions between epithelial and mesenchymal cells, imbalanced production of mediators and growth factors, and local mitogenic factors due to prolonged denudation of the basement membrane after injury. ${ }^{30}$ This process can potentially be altered or stopped, yielding a varying degree of histopathological changes, as seen in our cohort. Thus, the term postinfectious diffuse pulmonary disease might be a better term to reflect the spectrum of disease severity and would encompass a spectrum of changes from mild airway injury with only mild peribronchiolar or interstitial inflammation (as seen in our cohort) to severe airway fibrosis with significant luminal narrowing and to complete airway obliteration. However, further studies with detailed histological focus are needed to subgroup these children, which is difficult in this study as it covered almost two decades with loss or damage to some of the original histological slides.

Strengths of our study include the detailed description of our cohort, and the long follow-up period, including longterm longitudinal data. We investigated a unique cohort of children having a documented clinical history and diagnosis involving open lung biopsy and HRCT. Moreover, we included a panel of different advanced pulmonary function parameters, along with peak oxygen uptake, thus covering different aspects of airway function and overall physical fitness.

The primary limitation of this study is the small number of patients participating and the long timespan of diagnosis (1998-2015). Both limitations are often inevitable in research regarding rare diseases and lack of power to discover changes over time is a risk. Despite the long timespan, the overall basic diagnostic methods and treatment regimens have not been changed dramatically, although knowledge of diffuse lung diseases in children have increased significantly over the last 10 years-both clinically and in terms of histopathology. Additional inflammatory BAL profiles would have improved the study. Moreover, selection bias cannot be excluded since the follow-up study included only $50 \%$ of the entire cohort for different reasons. We also included two mild ex-premature patients who may have introduced other aspects of pulmonary disease not related to a postinfectious condition, but without history of bronchopulmonary dysplasia and therefore not considered clinically relevant.

Some of the cases were diagnosed many years ago, so it cannot be excluded that some represent NEHI, which is a relatively new diagnostic entity and requires special bombesin staining. ${ }^{31}$ However, this was not supported by clinical history, HRCT or histopathology. Open lung biopsy was performed in $93 \%$ of the patients. All lung biopsies include a risk of false negative results due to patchy distribution of structural changes, including postinfectious changes, but we consider this risk to be limited since all biopsies were guided by HRCT-documented structural abnormalities, and open lung biopsies in general provide a larger tissue yield. The severity of the biopsy findings was graded according to the subjective judgment of the pathologists since no clear objective classification exists, although such a system would have improved the study by a rereview of all the slides. However, some of the slides had age-related damage or were lost $(n=7)$. Another limitation is the use of a nonvalidated questionnaire to assess physical limitations and 
weekly physical activity and the lack of a healthy reference group for comparison. Rather than providing information about physical activity in general, the questions were related to the last 2 weeks; however, the results seem acceptable as they were correlated with the contemporary lung function data acquired at the follow-up visit. During the study period, no validated child-specific quality-of-life questionnaire was available, but this is currently under consideration within the child-EU project. ${ }^{32}$

Previous $\mathrm{N}_{2} \mathrm{MBW}$ measurements were unavailable; thus, we could not evaluate the development of $\mathrm{N}_{2} \mathrm{MBW}$ indices over time. Future studies should evaluate the use of $\mathrm{N}_{2} \mathrm{MBW}$ measurements for monitoring treatment effects and evolution in diffuse lung disease as demonstrated in previous studies from our center. ${ }^{20,23,33}$

The present study was focused on long-term follow-up and prognosis after treatment completion. The aim was not to evaluate specific individual treatment responses. Future studies are needed to investigate this aspect, especially in terms of the correlation to individual histopathological findings in surgical lung biopsy specimens. It would certainly be interesting to evaluate whether a "window of opportunity" exists, during which a failed and disorganized "repair track" can be altered or stopped to prevent irreversible lung damage, which carries a reported mortality rate of up to $18 \%$ during the acute phase in PIBO. ${ }^{1,8}$

Although our results revealed significant peripheral airway impairment below normal values, it did not seem to affect physical ability during follow-up. However, the subsequent natural decline in adulthood may lead to early development of a severe condition resembling COPD, which is similar to speculations concerning bronchopulmonary dysplasia. $^{34}$

\section{Conclusion}

Postinfectious diffuse pulmonary disease in children carries a varying degree of chronic pulmonary impairment with onset of symptoms in the first months of life and a typical considerable lag time before diagnosis. Follow-up of several years after the initial injury demonstrated moderateto-severe peripheral airway impairment although no further lung function decline was found after completion of treatment. Despite acceptable $\mathrm{VO}_{2 \text { peak }}$, a considerable proportion struggled during heavy exercise.

These findings support that the term postinfectious diffuse pulmonary disease covers a broader spectrum that do not seem to meet the criteria for the classical and more severe PIBO entity, but still represent significant chronic pulmonary impairment. There remains a need for further larger and possibly multicenter studies regarding early treatment intervention and continuous follow-up into adulthood to estimate the true long-term prognosis. Our study precedes newly initiated European strategies to fulfil such goals. ${ }^{33}$

\section{Acknowledgments}

The authors thank the patients and families for their participation in this study, as well as the staff of the Danish PCD \& chILD Centre and CF Centre Copenhagen Paediatric Pulmonary Service at Copenhagen University Hospital, Rigshospitalet. COST action: F.F.B and K.G.N. are Danish MC members of ENTeR chILD (COST Action CA16125).

\section{Author Disclosure Statement}

No competing financial interests exist.

\section{Supplementary Material}

Supplementary Data S1

Supplementary Data S2

Supplementary Data S3

Supplementary Figure S1

Supplementary Figure S2

Supplementary Figure S3

Supplementary Table S1

\section{References}

1. Fischer GB, Sarria EE, Mattiello R, et al. Post infectious bronchiolitis obliterans in children. Paediatr Respir Rev 2010; 11:233-239.

2. Moonnumakal SP, Fan LL. Bronchiolitis obliterans in children. Curr Opin Pediatr 2008; 20:272-278.

3. Smith KJ, Fan LL. Insights into post-infectious bronchiolitis obliterans in children. Thorax 2006; 61:462-463.

4. Kurland G, Michelson P. Bronchiolitis obliterans in children. Pediatr Pulmonol 2005; 39:193-208.

5. Zhang L, Irion K, da Silva Porto N, et al. High-resolution computed tomography in pediatric patients with postinfectious bronchiolitis obliterans. J Thorac Imaging 1999; 14:85-89.

6. Champs NS, Lasmar LM, Camargos PA, et al. Postinfectious bronchiolitis obliterans in children. J Pediatr 2011; 87:187-198.

7. Colom AJ, Maffey A, Garcia Bournissen F, et al. Pulmonary function of a paediatric cohort of patients with postinfectious bronchiolitis obliterans. A long term followup. Thorax 2015; 70:169-174.

8. Castro-Rodriguez JA, Daszenies C, Garcia M, et al. Adenovirus pneumonia in infants and factors for developing bronchiolitis obliterans: a 5-year follow-up. Pediatr Pulmonol 2006; 41:947-953.

9. Lang WR, Howden CW, Laws J, et al. Bronchopneumonia with serious sequelae in children with evidence of adenovirus type 21 infection. Br Med J 1969; 1:73-79.

10. Cazzato S, Poletti V, Bernardi F, et al. Airway inflammation and lung function decline in childhood post-infectious bronchiolitis obliterans. Pediatr Pulmonol 2008; 43:381390.

11. Cazzato S, di Palmo E, Ragazzo V, et al. Interstitial lung disease in children. Early Hum Dev 2013; 89 Suppl 3:S39S43.

12. Robinson PD, Goldman MD, Gustafsson PM. Inert gas washout: theoretical background and clinical utility in respiratory disease. Respiration 2009; 78:339-355.

13. Robinson PD, Latzin P, Verbanck S, et al. Consensus statement for inert gas washout measurement using multiple- and single- breath tests. Eur Respir J 2013; 41:507-522.

14. Houltz B, Green K, Lindblad A, et al. Tidal N2 washout ventilation inhomogeneity in a reference population aged 7-70 years. European Respiratory Society. Eur Respir J Suppl 2012;3797.

15. Miller MR, Hankinson J, Brusasco V, et al. Standardisation of spirometry. Eur Respir J 2005; 26:319-338.

16. Macintyre N, Crapo RO, Viegi G, et al. Standardisation of the single-breath determination of carbon monoxide uptake in the lung. Eur Respir J 2005; 26:720-735.

17. Stocks J, Quanjer PH. Reference values for residual volume, functional residual capacity and total lung capacity. 
ATS Workshop on Lung Volume Measurements. Official Statement of The European Respiratory Society. Eur Respir J 1995; 8:492-506.

18. American Thoracic Society. Single-breath carbon monoxide diffusing capacity (transfer factor). Recommendations for a standard technique-1995 update. Am J Respir Crit Care Med 1995; 152:2185-2198.

19. Pellegrino R, Viegi G, Brusasco V, et al. Interpretative strategies for lung function tests. Eur Respir J 2005; 26:948-968.

20. Madsen A, Green K, Buchvald F, et al. Aerobic fitness in children and young adults with primary ciliary dyskinesia. PLoS One 2013; 8:e71409.

21. Mattiello R, Sarria EE, Stein R, et al. Functional capacity assessment in children and adolescents with post-infectious bronchiolitis obliterans. J Pediatr 2008; 84:337-343.

22. Sisman Y, Buchvald F, Blyme AK, et al. Pulmonary function and fitness years after treatment for hypersensitivity pneumonitis during childhood. Pediatr Pulmonol 2016; 51:830-837.

23. Uhlving HH, Mathiesen S, Buchvald F, et al. Small airways dysfunction in long-term survivors of pediatric stem cell transplantation. Pediatr Pulmonol 2015; 50:704-712.

24. Kongstad T, Green K, Buchvald F, et al. Association between spirometry controlled chest CT scores using computer-animated biofeedback and clinical markers of lung disease in children with cystic fibrosis. Eur Clin Respir J 2017; 4:1318027.

25. Milani RV, Lavie CJ, Mehra MR, et al. Understanding the basics of cardiopulmonary exercise testing. Mayo Clinic Proc 2006; 81:1603-1611.

26. Colom AJ, Teper AM, Vollmer WM, et al. Risk factors for the development of bronchiolitis obliterans in children with bronchiolitis. Thorax 2006; 61:503-506.

27. Zhang L, Irion K, Kozakewich H, et al. Clinical course of postinfectious bronchiolitis obliterans. Pediatr Pulmonol 2000; 29:341-350.
28. Fischer GB, Teper A, Colom AJ. Acute viral bronchiolitis and its sequelae in developing countries. Paediatr Respir Rev 2002; 3:298-302.

29. Ryu JH, Myers JL, Swensen SJ. Bronchiolar disorders. Am J Respir Crit Care Med 2003; 168:1277-1292.

30. Clement A, Eber E. Interstitial lung diseases in infants and children. Eur Respir J 2008; 31:658-666.

31. Deterding RR, Pye C, Fan LL, et al. Persistent tachypnea of infancy is associated with neuroendocrine cell hyperplasia. Pediatr Pulmonol 2005; 40:157-165.

32. Griese M, Seidl E, Hengst M, et al. International management platform for children's interstitial lung disease (chILD-EU). Thorax 2018; 73:231-239.

33. Green K, Buchvald FF, Marthin JK, et al. Ventilation inhomogeneity in children with primary ciliary dyskinesia. Thorax 2012; 67:49-53.

34. Jensen EA, Schmidt B. Epidemiology of bronchopulmonary dysplasia. Birth Defects Res A Clin Mol Teratol 2014; 100:145-157.

Address correspondence to: Kim Gjerum Nielsen, MD, DMSc

Danish chILD Centre

Paediatric Pulmonary Service Copenhagen University Hospital Rigshospitalet Blegdamsvej 9 2100 Copenhagen Denmark

E-mail: kgn@dadlnet.dk

Received for publication November 18, 2018; accepted after revision February 10, 2019. 